\title{
A ELITE DERROTADA- UMA ANÁLISE DO FRACASSO ELEITORAL DOS DEPUTADOS ESTADUAIS NAS (RE)ELEIÇÕES DE 2018 NO PARANÁ
}

\author{
Gabriel Marcondes de Moura ${ }^{1}$ \\ Breno Pacheco Leandro ${ }^{2}$
}

\begin{abstract}
Resumo
Este artigo trata do insucesso eleitoral dos incumbentes que disputaram a reeleição para deputado estadual nas eleições de 2018 no Estado do Paraná. O objetivo é investigar se há similaridades entre o perfil dos candidatos derrotados. A pesquisa foi realizada comparando o desempenho eleitoral dos 13 candidatos derrotados entre os deputados que tentaram reeleição no pleito de 2018. As hipóteses são: (I) que os derrotados compartilham um perfil prosopográfico semelhante; (II) diante da ascensão de novas forças políticas no cenário político de 2018, a erosão do capital político desses candidatos refletiu-se na perda de votos de uma eleição para a outra, culminando na derrota no pleito, e; (III) a opção pela migração partidária no caso dos incumbentes analisados desfavoreceu a conquista da reeleição. Os dados foram coletados do repositório do TSE, no site da ALEP, notícias e páginas online dos candidatos. Os resultados sobre os incumbentes foram obtidos pelas análises prosopográfica e cálculos de desempenho eleitoral, onde constatou-se que (a) profissionalização política e (b) alto número de mandatos consecutivos de candidatos com duas ou mais legislaturas foram significativas no perfil em comum dos derrotados; da mesma forma, a análise desempenho eleitoral vai de encontro à hipótese (II) ao apontar para uma considerável erosão de capital político por parte dos incumbentes, uma vez que todos perderam em média a 27,5\% dos votos de uma eleição a outra, superior a 1/4 da votação anterior; enquanto a hipótese (III) não se sustenta à luz das informações sobre migração partidária, uma vez que sete incumbentes optaram por ela, e outros seis se mantiveram fiéis aos seus partidos originários.
\end{abstract}

Palavras-Chave: Reeleição; Derrotados; Desempenho Eleitoral; Deputados Estaduais; Paraná.

\section{INTRODUÇÃO}

A elite política vem sido estudada ao longo da história (MILLS, 1968), e no caso brasileiro, ganha notoriedade quando observamos as singularidades do sistema eleitoral, principalmente em relação aos candidatos e a composição das casas legislativas (RODRIGUES, 2002). Trabalhos sobre a Câmara Federal trazem apontamentos únicos sobre esta dinâmica, e sobre aqueles que se profissionalizam e competem a reeleição (MANCUSO et al. 2013; PARANHOS et al., 2014). Porém,

\footnotetext{
${ }^{1}$ Mestrando (PPGCP-UFPR) vinculado ao Laboratório de Partidos Políticos e Sistemas Partidários (LAPeS), gmmcipol@gmail.com e ORCID: https://orcid.org/0000-0002-0913-5468

2 Doutorando (PPGCP-UFPR) vinculado ao Laboratório de Partidos Políticos e Sistemas Partidários (LAPeS), bpachecoleandro@gmail.com e ORCID: https://orcid.org/0000-0001-5076-404X.
} 
mesmo nestes artigos icônicos, nos holofotes de análises encontram-se os vitoriosos dos pleitos. Mas fenômenos recentes chamam atenção.

Nas eleições de 2018, o fenômeno de maior destaque foi a candidatura à presidência da república capitaneada por Jair Bolsonaro, estando a frente do Partido Social Liberal (PSL). Seu desempenho na eleição majoritária nacional repercutiu nas eleições proporcionais, tanto a nível federal, como estadual. Tendo esta premissa como ponto de partida, analisaremos o caso da Assembleia Legislativa do Paraná (ALEP), mais especificamente o desempenho eleitoral dos incumbentes que tentaram a reeleição e não obtiveram sucesso, algo pouco debatido na literatura, visto que usualmente interpretamos dados dos eleitos.

Os resultados das eleições demonstraram que ocorreu coattail effect ${ }^{3}$, porém, segundo Leandro e Moura (2019), a renovação parlamentar e o efeito do PSL entre os deputados estaduais não conseguiram impactar de maneira significativa na renovação líquida obtida. Segundos os autores, mesmo com a votação expressiva do PSL, na figura do candidato Delegado Francischini (deputado eleito com maior número de votos nominais em uma eleição para ALEP), e puxando consigo mais oito cadeiras, verificou-se que a renovação foi compulsória- renovação das vagas deixadas em aberto pelos desistentes. Outro fator de destaque, foi a presença marcante de candidatos de carreirismo policial: cinco dos oito deputados eleitos. Entre a comparação do pleito de 2014 e de 2018, as taxas de renovação foram similares, ou seja, mesmo com o efeito PSL não tivemos grandes reestruturações.

O espaço conquistado pelo PSL se deu principalmente pela erosão de partidos de centrodireita como PSD, PSC e o PSDB (partido que sofreu maior desgaste em suas bases eleitorais entre a $18^{\mathrm{a}}$ e a $19^{\mathrm{a}}$ legislatura). Visto estas singularidades das eleições 2018 , as seguintes questões nos são apresentadas: quem são os deputados(as) derrotados(as), qual desempenho eleitoral obtiveram, e quais as possíveis razões explicativas para a não reeleição?

No total 13 incumbentes de sete partidos diferentes (DEM, MDB, PT, PRP, PSD, PSC e PSDB) não conseguiram a reeleição (12 não eleitos e um suplente) entre as eleições de 2014 e 2018, representando $28 \%$ de fracasso entre os incumbentes, resultado muito próximo ao encontrado para os deputados federais de 30\% entre 1998 à 2010 (PARANHOS et al., 2014, p.12) . Os casos ${ }^{4}$ a serem analisados são: Adelino Ribeiro (PRP), Ademir Bier (PSD), Alexandre Guimarães (PSD), André Bueno (PSDB), Cantora Mara Lima (PSC), Claudia Pereira (PSC), Cláudio Palozi (PSC), Elio Rusch

\footnotetext{
3 “É um fenômeno pelo qual a popularidade de um candidato ou líder político leva a melhores totais de votos para candidatos a partidos mais adiante." (vide Political Dictionary, 2018. Verbete: Coattail Effect. Disponível em: <https://politicaldictionary.com/words/coattail-effect/>. Acesso em: 02 de jun. de 2020)

${ }^{4}$ Nomes de urna.
} 
(DEM), Evandro Junior (PSDB), Hussein Bakri (PSD), Nereu Moura (MDB) ${ }^{5}$, Péricles de Mello (PT) e Wilson Quinteiro (PSDB) ${ }^{6}$. Esse conjunto de indivíduos, junto com a premissa e a definição de que a prosopografia é uma biografia coletiva (HEINZ; CODATO, 2015), constitui-se na amostragem para apurar o perfil dos incumbentes derrotados em 2018 no Paraná, bem como seus respectivos desempenhos eleitorais.

Considerando que a reeleição é favorecida pelo capital político acumulado pelo incumbente em termos eleitorais, e é desfavorecida pela migração partidária (MANCUSO et al., 2013), nossas hipóteses para a não reeleição dos incumbentes vão no mesmo sentido: (I) os derrotados compartilham um perfil prosopográfico semelhante; (II) diante da ascensão de novas forças políticas no cenário político de 2018, a erosão do capital político desses candidatos refletiu-se na perda de votos de uma eleição para a outra, culminando na derrota no pleito, e; (III) a opção pela migração partidária no caso dos incumbentes analisados desfavoreceu a conquista da reeleição.

A base de dados do artigo foi desenvolvida com informações públicas, disponibilizadas no site do Repositório de Dados Eleitorais do Tribunal Superior Eleitoral (TSE), e organizadas com o software Microsoft Excel. As explorações foram compostas de análise qualitativa e estatísticas descritivas.

\section{QUEM SÃO OS DERROTADOS}

Afim de contribuir com a literatura, as hipóteses são que o desempenho e os perfis destes candidatos são similares. E para verificação deste argumento, o método utilizado será a descrição prosopográfica. Como destacado em Stone (2011), a prosopografia seria:

[A prosopografia é] a investigação das características comuns de um grupo de atores na história por meio de um estudo coletivo de suas vidas. O método empregado constitui em estabelecer um universo a ser estudado e então investigar um conjunto de questões uniformes[...] (STONE, 2011, p.115)

As principais dificuldades apontadas pelos especialistas neste tipo de metodologia são as coletas e formatação dos dados. Por exemplo, identificar determinadas informações de candidatos com dificuldades apercebidas, escassez dos dados ou problemas analíticos com as características

\footnotetext{
${ }^{5}$ Suplente em 1990, assumiu cadeira em 1993.

${ }^{6}$ Suplente em 2006, assumiu cadeira em 2009. Suplente em 2010, assumiu cadeira em 2013. Suplente em 2014, assumiu cadeira em 2018.
} 
socioprofissionais ou de background político (STONE, 2011; HEINZ; CODATO, 2015). Outra questão é o fator temporal, quanto mais antigo e sem notoriedade for o indivíduo, maiores dificuldades na busca pelas informações. Porém, no recorte deste artigo, devido ao seu escopo recente e de nível estadual houveram poucas dificuldades na cotização dos candidatos não eleitos. De forma concentrada e coesa, buscou-se relevância principalmente em fatores políticos dos ex-deputados(as), como número de mandatos. Enquanto o perfil socioprofissional corrobora e principalmente destacar que como encontrado anteriormente, as eleições de 2018 tiveram uma crescente em deputados que usufruíram de associações com a carreia e titulações militares, frisados em seus nomes de urna, enquanto todos derrotados não possuíam está característica (LEANDRO; MOURA, 2019).

Outro fator relevante sobre os deputados não eleitos é que apenas quatro dos 13 candidatos, estavam em sua primeira legislatura. Excluindo estes casos, a média do número de mandatos completos consecutivos ficou em 3,6 (mandatos). Apenas o ex-deputado Wilson Quinteiro (PSDB) não se encaixa no cálculo, das três vezes que assumiu uma cadeira, todas foram devidas a suplência.

Acerca da idade, foram utilizados os anos de vida do candidato no momento da eleição (2018). E apenas um concorrente possui menos de 40 anos, ex-deputado Evandro Junior (PSDB) com 30 anos, e o mais velho ex-deputado Ademir Bier (PSD), com 67 anos. A média de faixa etária ficou em 53 $\operatorname{anos}^{7}$. E na categorização de cor/raça, $85 \%$ dos fracassados declararam branco(a), taxa próxima aos eleitos (87\%). A escolaridade média entre os não eleitos ficou principalmente no ensino superior incompleto e completo, 10 ao todo (três incompleto e sete completo); os outros três casos possuem ensino médio completo. Segundo Coradini (2012), que analisou eleições legislativas de 2004 e eleições gerais de 2006, este tipo de informação se acentua quando comparamos as esferas políticas.

[...] os candidatos a Senador não eleitos têm uma quantidade muito pequena $(0,6 \%)$ dos que apenas lêem e escrevem e bem mais da metade $(66,87 \%)$ com curso superior completo e a situação dos candidatos não eleitos a Governador, a Deputado Federal e a Deputado Estadual é semelhante. (CORADINI, 2012, p.113)

Esta afirmação argumenta que quanto maior a escala política no legislativo de vereador à deputados federais, maior é o grau de instrução (tanto nos eleitos, como não eleitos). Mais um destaque ocorreu na autodeclaração de ocupação dos candidatos. Dentre os 13 casos, apenas Alexandre Guimarães (PSD) não se proclamou como “deputado”. Em Perissinotto e Bolognesi (2010), a variável mais importante para o sucesso eleitoral na Câmara de Deputados (1998, 2002 e 2006) é

\footnotetext{
${ }^{7}$ Segundo o TSE, a faixa etária entre 50 a 54 anos, foi a maior entre classificação pré-estabelecida, totalizando $16,15 \%$ de todas as candidaturas para o Estado do Paraná. (vide Estatísticas Eleitorais. http://www.tse.jus.br/eleicoes/estatisticas/estatisticas-eleitorais. Acessado em 05 de julho de 2020.)
} 
ser político profissional. E ainda destacam dois pontos a respeito: o avanço no processo de institucionalização; e a experiência prévia como filtro no modo de seleção dos candidatos (p.12). Porém, como denotado anteriormente, apenas quatro candidatos estavam em seu primeiro mandato e em um dos casos, Élio Rusch (DEM), possuía sete mandatos consecutivos na ALEP.

Além de que, dos 13 incumbentes, sete candidatos mudaram de partidos antes da disputa da reeleição. E sobre as trocas, nenhuma delas foram eventuais ao partido em destaque na eleição 2018, PSL. Ainda sobre partidos, duas coligações perderam veemente com a derrota nas urnas destes incumbentes: Inova Paraná (PSD/PSC) e Paraná Firme (PP, PTB, DEM, PSDB e PSB), totalizando 10 candidatos entre estas coligações. Como destacado em Paranhos et al. (2014), as mudanças partidárias e as desistências são dois fatores que contribuem com a dificuldade dos partidos de assegurar o voto anterior, característica do personalismo existente nas disputas legislativas.

Dentro do recorte selecionado de não eleitos, profissionalização política não foi uma variável negativa. Excluindo fatores externos, como a ascensão dos militares, por exemplo, será que houve uma queda no desempenho individual destes candidatos em distritos eleitorais?

\section{O DESEMPENHO ELEITORAL DOS NÃO ELEITOS}

Os dados necessários para a elaboração deste trabalho são públicos e foram obtidos no site do Repositório de Dados Eleitorais do Tribunal Superior Eleitoral (TSE). Os dados brutos foram organizados e refinados com a aplicação do software Microsoft Excel. Para a análise desses dados utiliza-se apenas a aplicação de estatística descritiva.

Primeiramente, é necessário compreender a dimensão da variação e da diferença de votos dos 13 casos analisados entre as eleições de 2014 e 2018. Na tabela 1, a coluna "V.14" refere-se a votação do deputado nas eleições de 2014; da mesma forma, a coluna "V.18" refere-se a votação do deputado nas eleições 2018; a coluna "M / P” refere-se a opção do candidato pela migração partidária entre as duas eleições ou não; a coluna "VAR." representa a variação total de votos dos candidatos entre as eleições de 2014 e 2018, e; a coluna “\%” refere-se a variação percentual do total de votos dos candidatos entre as eleições 2014 e 2018. 
Tabela 1 - Desempenho Eleitoral (2014-2018)

\begin{tabular}{l|rrrrr}
\multicolumn{1}{c}{ DEPUTADO } & V.14 & V. 18 & M / P & VAR. & \% \\
\hline Adelino Ribeiro & 42924 & 37835 & SIM & -5089 & $-11,86 \%$ \\
Ademir Bier & 45699 & 26015 & SIM & -19684 & $-43,07 \%$ \\
Alexandre Guimarães & 24357 & 25300 & SIM & $\underline{943}$ & $\underline{3,87 \%}$ \\
André Bueno & 36506 & 26955 & SIM & -9551 & $-26,16 \%$ \\
Cantora Mara Lima & 43549 & 33866 & SIM & -9683 & $-22,23 \%$ \\
Cláudia Pereira & 29379 & 22428 & NÃO & -6951 & $-23,66 \%$ \\
Cláudio Palozi & 39364 & 22691 & NÃO & -16673 & $-42,36 \%$ \\
Élio Rusch & 54993 & 32001 & NÃO & -22992 & $-41,81 \%$ \\
Evandro Jr. & 64467 & 31200 & NÃO & -33267 & $-51,60 \%$ \\
Hussein Bakri & 26682 & 32679 & SIM & $\underline{5997}$ & $\underline{22,48 \%}$ \\
Nereu Moura & 48735 & 35479 & NÃO & -13256 & $-27,20 \%$ \\
Péricles de Melo & 40966 & 27397 & NÃO & -13569 & $-33,12 \%$ \\
Wilson Quinteiro & 41195 & 15491 & SIM & -25704 & $-62,40 \%$
\end{tabular}

FONTE: Os autores, 2020.

Conforme a Tabela 1 nos apresenta, 07 dos 13 deputados optaram pela migração partidária, considerando ser pouco mais da metade dos incumbentes, torna-se insegura a afirmação de que a migração partidária tenha exercido de fato peso determinante no fracasso eleitoral dos candidatos.

Também constatamos que os 13 incumbentes perderam em média 13.000 votos de uma eleição a outra, mesmo com alguns apresentando um modesto aumento de votos, como no caso dos incumbentes Alexandre Guimarães (PSD) e Hussein Bakri (PSD). Em termos percentuais, esta perda apresenta a média de $27,5 \%$ dos votos, ou seja, a maioria desses incumbentes apresentaram uma perda superior a 1/4 da votação obtida nas eleições de 2014.

A análise da votação total dos candidatos nos oferece a compreensão do tamanho da perda de votos dos incumbentes que disputaram a reeleição e foram derrotados, porém, trata-se da votação agregada em todo o Estado do Paraná. É preciso analisar também os casos em particular e o desempenho eleitoral destes candidatos em suas respectivas bases eleitorais, ou seja, nos municípios que mais contribuíram com votos para a eleição destes deputados nas eleições de 2014, e comparar com os resultados obtidos nas eleições de 2018. Desta forma, nos é possível compreender melhor o desempenho eleitoral dos candidatos analisados entre as duas eleições.

Na tabela 2, a coluna "MUNICÍPIO" refere-se ao município onde determinado candidato obteve a maior votação nominal dentre os 399 municípios do Estado, constituindo-se assim em sua principal base eleitoral, ou a mais expressiva a contribuir com votos nas eleições de 2014 e, na grande 
maioria dos casos, nas eleições de $2018^{8}$ também; as colunas "P.14" e "P.18" indicam a posição do incumbente entre os candidatos mais votados naquela municipalidade nas eleições de 2014 e 2018 respectivamente; as colunas "V.14" e "V.18" indicam a votação do candidato naquela municipalidade nas eleições 2014 e 2018 respectivamente; a coluna "VAR." indica a variação da votação total entre uma eleição e outra no determinado município, e; a coluna “\%” indica a variação percentual da diferença de votos entre as eleições 2014 e 2018.

Tabela 2 - Desempenho Eleitoral no Município Principal

\begin{tabular}{|c|c|c|c|c|c|c|c|}
\hline DEPUTADO & MUNICÍPIO & $\begin{array}{l}P . \\
14\end{array}$ & V. 14 & $\begin{array}{l}\text { P. } \\
18\end{array}$ & V. 18 & VAR. & $\%$ \\
\hline Adelino Ribeiro & Cascavel & $2^{\circ}$ & 23486 & $3^{\circ}$ & 16101 & - 7.385 & $-31,44 \%$ \\
\hline Ademir Bier & M. C. Rondon ${ }^{9}$ & $1^{\mathrm{o}}$ & 12331 & $2^{o}$ & 5848 & - 6.483 & $-52,57 \%$ \\
\hline Alexandre Guimarães & Campo Largo & $1^{\mathrm{o}}$ & 16827 & $3^{\circ}$ & 6601 & -10.226 & $-60,77 \%$ \\
\hline André Bueno & Cascavel & $3^{\circ}$ & 21082 & $7^{\circ}$ & 7601 & -13.481 & $-63,95 \%$ \\
\hline Cantora Mara Lima & Curitiba & $18^{\circ}$ & 9587 & $35^{\circ}$ & 5190 & - 4.397 & $-45,86 \%$ \\
\hline Cláudia Pereira & Foz do Iguaçu & $2^{\circ}$ & 17112 & $11^{\circ}$ & 991 & -16.121 & $-94,21 \%$ \\
\hline Cláudio Palozi & Umuarama & $3^{\circ}$ & 10003 & $5^{\mathrm{o}}$ & 3096 & - 6.907 & $-69,05 \%$ \\
\hline Élio Rusch & M. C. Rondon & $2^{\circ}$ & 9251 & $\underline{1^{\mathrm{o}}}$ & $\underline{7338}$ & $\begin{array}{r}-\quad 1.913 \\
\end{array}$ & $-20,68 \%$ \\
\hline Evandro Jr. & Maringá & $6^{\circ}$ & 13144 & $13^{\circ}$ & $\overline{3366}$ & -9.778 & $-74,39 \%$ \\
\hline Hussein Bakri & U. da Vitória ${ }^{10}$ & $1^{\mathrm{o}}$ & 14282 & $\underline{1}^{\mathrm{o}}$ & $\underline{11489}$ & $\begin{array}{r}-\quad 2.793 \\
\end{array}$ & $-19,56 \%$ \\
\hline Nereu Moura & Nova Aurora & $1^{\mathrm{o}}$ & 2546 & $4^{\circ}$ & 629 & - 1.917 & $-75,29 \%$ \\
\hline Péricles de Melo & Ponta Grossa & $3^{o}$ & 25402 & $4^{\circ}$ & 12972 & -12.430 & $-48,93 \%$ \\
\hline Wilson Quinteiro & Maringá & $2^{\mathrm{o}}$ & 22728 & $9^{\circ}$ & 7602 & -15.126 & $-66,55 \%$ \\
\hline
\end{tabular}

FONTE: Os autores, 2020.

Nos municípios onde os 13 incumbentes apresentaram o melhor desempenho nas eleições de 2014, onde presume-se se tratar da base eleitoral mais forte dos deputados estaduais, todos amargaram queda no desempenho eleitoral, chegando à média de 8.300 votos de uma eleição a outra. Em termos representativos, os incumbentes derrotados viram desidratar em média 55,6\% dos votos obtidos em sua principal base eleitoral de uma eleição a outra. Esta perda percentual é maior que a média em relação a votação total, o que nos apresenta o fato de que todos os incumbentes derrotados perderam votos em suas principais cidades, e podemos aferir também que a maioria, ou seja, 08 dos 13 casos

\footnotetext{
${ }^{8}$ Apenas os deputados Cláudia Pereira e Nereu Moura alteraram os municípios onde obtiveram maior votação nominal de uma eleição a outra. Cláudia Pereira obteve 17.112 votos nas eleições de 2014 no município de Foz do Iguaçu, e 3.867 votos em Curitiba nas eleições de 2018. O deputado Nereu Moura obteve 2.546 votos no município de Nova Aurora nas eleições de 2014, e nas eleições de 2018 obteve 2.713 votos no município de Wenceslau Braz.

${ }^{9}$ Abreviação para: Marechal Cândido Rondon/PR.

${ }^{10}$ Abreviação para: União da Vitória/PR.
} 
analisados tiveram em comum a perda considerável de votos, acima da casa dos $50 \%$ em suas principais bases eleitorais.

Talvez a mitigação dos votos perdidos nos principais redutos eleitorais destes incumbentes pudesse ser recompensada com uma dispersão de votos por outros municípios e regiões, à fim de compensar as perdas e de expandir o capital político do deputado pelo restante do Estado. Para tanto, na Tabela 3 comparamos a flutuação dos votos dos incumbentes na base eleitoral com a flutuação dos votos nos demais municípios do Estado.

Tabela 3 - Desempenho Eleitoral: Base Eleitoral x Restante do Estado (2014-2018) ${ }^{11}$

\begin{tabular}{l|rrrrrrrr}
\multicolumn{1}{c}{ DEPUTADO } & BE 14 & OM 14 & BE 18 & OM 18 & \multicolumn{1}{c}{ BE V } & OM V & BE \% & OM \% \\
\hline Adelino Ribeiro & 23486 & 19438 & 16101 & 21734 & -7.385 & $\underline{2296}$ & $-31,44 \%$ & $\underline{15,34 \%}$ \\
Ademir Bier & 12331 & 33368 & 5848 & 20167 & -6.483 & -13201 & $-52,57 \%$ & $-39,56 \%$ \\
Alexandre Guimarães & 16827 & 7530 & 6601 & 18699 & -10.226 & $\underline{11169}$ & $-60,77 \%$ & $\underline{148,33 \%}$ \\
André Bueno & 21082 & 15424 & 7601 & 19354 & -13.481 & $\underline{3930}$ & $-63,95 \%$ & $\underline{25,48 \%}$ \\
Cantora Mara Lima & 9587 & 33962 & 5190 & 28676 & -4.397 & -5286 & $-45,86 \%$ & $-15,56 \%$ \\
Cláudia Pereira & 17112 & 12267 & 991 & 21437 & -16.121 & $\underline{9170}$ & $-94,21 \%$ & $\underline{74,75 \%}$ \\
Cláudio Palozi & 10003 & 29361 & 3096 & 19595 & -6.907 & -9766 & $-69,05 \%$ & $-33,26 \%$ \\
Élio Rusch & 9251 & 45742 & 7338 & 24663 & -1.913 & -21079 & $-20,68 \%$ & $-46,08 \%$ \\
Evandro Jr. & 13144 & 51323 & 3366 & 27834 & -9.778 & -23489 & $-74,39 \%$ & $-45,77 \%$ \\
Hussein Bakri & 14282 & 12400 & 11489 & 21190 & -2.793 & $\underline{8790}$ & $-19,56 \%$ & $\underline{70,89 \%}$ \\
Nereu Moura & 2546 & 46189 & 629 & 34850 & -1.917 & -11339 & $-75,29 \%$ & $-24,55 \%$ \\
Péricles de Melo & 25402 & 15564 & 12972 & 14425 & -12.430 & -1139 & $-48,93 \%$ & $-7,32 \%$ \\
Wilson Quinteiro & 22728 & 18467 & 7602 & 7889 & -15.126 & -10578 & $-66,55 \%$ & $-57,28 \%$
\end{tabular}

FONTE: Os autores, 2020.

Os autores apontados (MANCUSO et al., 2013; PARANHOS et al., 2014) demonstram que o processo de reeleição depende de variáveis pra além da reciprocidade dos votos com as bases eleitorais. O desempenho eleitoral depende de fatores como: a disputa dos votos dos desistentes; a mudança de partido visando expansão de votos ou o impacto gerado no quociente partidário por outros candidatos; e principalmente na campanha estadual para o angariamento de votos de outros municípios pra além de seu distrito eleitoral (como demonstrado nas Tabelas 2 e 3). O accountability deve possuir saldo positivo para os eleitores, afinal, a urna pune.

\footnotetext{
${ }^{11}$ Nesta tabela, BE é a abreviação para a votação do candidato no município que mais contribuiu para sua votação final, constituindo-se assim em sua principal Base Eleitoral; enquanto OM é a soma da votação obtida por determinado candidato em Outros Municípios do Estado do Paraná.
} 


\section{CONSIDERAÇÕES FINAIS}

O fenômeno causado pelo candidato à presidência da república, Jair Bolsonaro frente ao Partido Social Liberal (PSL), afetou diretamente as eleições tanto no nível federal, como estadual, nas eleições de 2018. A partir destas perspectivas, ao olhar para Assembleia Legislativa do Paraná (ALEP), foi visto que não houve renovação líquida impactante. Porém, dos 46 candidatos que tentaram a reeleição, 13 não atingiram o sucesso eleitoral. Entre os não eleitos, uma das hipóteses era que havia similaridades.

Sobre o perfil socioprofissional corrobora e destaca que nas eleições de 2018, houve uma crescente em deputados que usufruíram de associações com a carreia e titulações militares, frisados em seus nomes de urna, enquanto todos derrotados não possuíam está característica. Em relação a faixa etária, a média ficou em 53 anos. E na categorização de cor/raça, 85\% dos fracassados declararam branco(a), taxa próxima aos eleitos (87\%). A escolaridade entre os não eleitos ficou principalmente no ensino superior incompleto e completo, 10 ao todo (três incompleto e sete completo); os outros três casos com ensino médio completo. Outro fator relevante sobre os deputados não eleitos é que apenas quatro dos 13 candidatos, estavam em sua primeira legislatura. Excluindo estes casos, a média do número de mandatos completos consecutivos ficou em 3,6 (mandatos). Dentro do recorte selecionado de não eleitos, profissionalização política não foi uma variável negativa. $\mathrm{E}$ isso se destaca quando visualizado a média dos fracassados com dois ou mais mandatos consecutivos. A hipótese que (I) os derrotados compartilham um perfil prosopográfico semelhante, se confirma, principalmente em dois fatores principais: (a) alta profissionalização política; e (b) alto número de mandatos consecutivos de candidatos com duas ou mais legislaturas ${ }^{12}$.

Assim como é correta a afirmação de que é necessário capital político para satisfazer a ambição de avançar na carreira (MIGUEL, 2003), também se mostra fundamental conservar e ampliar o capital político à fim de satisfazer a ambição de se reeleger. Os dados analisados sobre o desempenho eleitoral vão de encontro à hipótese (II), ao apontar para uma considerável erosão de capital político por parte dos incumbentes, uma vez que todos perderam em média a $27,5 \%$ dos votos de uma eleição a outra, superior a 1/4 da votação anterior. Esta perda também foi mais significativa no principal reduto eleitoral dos candidatos, naqueles municípios que mais contribuíram para a votação geral dos candidatos nas eleições de 2014, chegando a uma perda média de 55,6\% por candidato. Tal

\footnotetext{
${ }^{12}$ Arredondando, número próximo a quatro mandatos.
} 
perda não foi recompensada com a dispersão da votação dos candidatos, uma vez que, com a exceção de quatro incumbentes, todos os outros também registraram perdas consideráveis no resto do Estado, sendo que até mesmo os que conseguiram atingir um saldo positivo, não alcançaram o suficiente para fazer a diferença no resultado eleitoral. Por outro lado, a hipótese (III) não se sustenta à luz das informações sobre migração partidária, uma vez que sete deputados optaram por ela, e outros seis se mantiveram fiéis aos seus partidos originários.

Amargando tais resultados negativos entre as duas eleições, esses candidatos só conseguiriam se reeleger caso estivessem em coligações mais favoráveis, como, por exemplo, a coligação PSL/PTC/PATRI, dado que o último eleito pela coligação atingiu a marca de 13.047 votos. Isto só foi possível dado o coattail effect exercido pela campanha presidencial de Jair Bolsonaro (PSL) sobre o voto de legenda (57.493 votos) e em candidatos do partido, como também pela votação obtida pelo deputado estadual Delegado Francischini (PSL), que alcançou a maior votação nominal não só no pleito, como também entre todas as eleições para o cargo com os seus 427.729 votos (52,90\% dos 808.458 votos obtidos pela coligação).

Feita estas considerações, a agenda de pesquisa assegura um campo de exploração a cerca de outros fatores que ainda não foram computados e analisados. Por exemplo, quem são estes outsiders que garantiram um lugar legislativo frente as ditas "raposas políticas"? Poderiam investigar comparativamente se há correlação entre a erosão da capital político dos incumbentes derrotados com a votação dos candidatos estreantes no parlamento, principalmente dos quadros que se autointitulam postulantes da "nova política". Outra possibilidade seria comparar o peso da migração partidária para o sucesso ou insucesso dos incumbentes acrescentando à analise o desempenho eleitoral dos que obtiveram êxito em garantir a reeleição. 


\section{REFERÊNCIAS}

CORADINI, Odaci Luiz. Categorias sócio-profissionais, titulação escolar e disputas eleitorais. Revista de Sociologia e Política, Curitiba, v. 20, n. 41, p. 109, 2012.

COSTA, Luiz Domingos; BOLOGNESI, Bruno. "O Sistema Partidário no Paraná: do Personalismo à Estruturação." Revista Debates 8.1 (2014): 221-243.

HEINZ, Flavio; CODATO, Adriano. A prosopografia explicada para cientistas políticos. Como estudar elites. Curitiba: Ed. UFPR, 2015.

LEANDRO, Breno Pacheco; MOURA, Gabriel Marcondes de. ELEIÇÕES 2018 NO PARANÁ: MENSURANDO O EFEITO PSL E SEU IMPACTO NA RENOVAÇÃO PARLAMENTAR DA ASSEMBLEIA LEGISLATIVA. Revista do Legislativo Paranaense, n. 3, p. 73-90, 2019.

MANCUSO, Wagner et al. Determinantes dos padrões de carreira política dos deputados federais paulistas entre as legislaturas 49a (1991-1995) e 53 (2007-2011). Opinião Pública. Campinas, v. 19, n 2, p. 430-448, 2013.

MIGUEL, Luís Felipe. Capital Político e Carreira Eleitoral: algumas variáveis na eleição para o congresso brasileiro. Revista de Sociologia Política, Curitiba, v. 20, p. 115-134, jun. 2003.

MILLS, C. Wright. A elite no poder. Rio de Janeiro, RJ: Zahar Ed, 1962.

PARANHOS, Ranulfo et al. Onde os fracos não tem vez: reeleição parlamentar no Brasil (19942010). 2014.

PERISSINOTTO, Renato; BOLOGNESI, Bruno. Electoral success and political institutionalization in the Federal Deputy elections in Brazil (1998, 2002 and 2006). Brazilian Political Science Review (Online), v. 5, n. SE, p. 0-0, 2010.

RODRIGUES, L. M. . Partidos, Ideologia e Composição Social. Rio de Janeiro, Edição on-line: Centro Edelstein de Pesquisas Sociais, 2009.

STONE, Lawrence. Prosopografia. Revista de Sociologia e Política, v. 19, n. 39, p. 115-137, 2011. 